\title{
Optimal timing of ventricular septal defect repair: Is it worth the weight?
}

\author{
Nicholas D. Andersen, MD, and Joseph W. Turek, MD, PhD
}

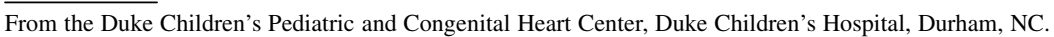

Disclosures: Authors have nothing to disclose with regard to commercial support.

Received for publication Dec 9, 2018; accepted for publication Dec 10, 2018; available ahead of print Jan 9, 2019.

Address for reprints: Nicholas D. Andersen, MD, Division of Cardiovascular and Thoracic Surgery, Duke University Medical Center, 2301 Erwin Rd, DUMC 3443, Durham, NC 27710 (E-mail: Nicholas.Andersen@ Duke.edu).

J Thorac Cardiovasc Surg 2019;157:1142-3

$0022-5223 / \$ 36.00$

Copyright $(c) 2018$ by The American Association for Thoracic Surgery

https://doi.org/10.1016/j.jtcvs.2018.12.029

\section{Cardiologist: "Doctor, you need to book this child for VSD repair.” \\ Surgeon: "Can it wait?" \\ Cardiologist: "No. The child is not gaining weight."}

Isolated ventricular septal defect (VSD) repair is the most common index operation performed by congenital heart surgeons in the United States, and the scenario described should ring familiar to all who treat this lesion. Although generally considered a safe operation, careful patient selection and preoperative management are required to ensure excellent outcomes. One vexing question is the optimal timing of operation related to patient age and weight. Children with large VSDs or severe heart failure symptoms often end up stuck on escalating diuretic and feeding regimens in an attempt to gain weight and theoretically reduce the risk profile of the operation. Is this necessary and are outcomes of VSD repair really affected by patient weight at the time of operation in contemporary practice?

In the current issue of the Journal, Inohara and colleagues ${ }^{1}$ queried the Japanese Cardiovascular Surgery Database for all children less than 1 year of age with a primary diagnosis of VSD who underwent surgical VSD closure or pulmonary artery banding. A total of 4947 patients were identified from 121 centers. The risk-adjusted association between body weight at the time of surgery and a composite end point of all-cause death and major complications within 30 days of surgery was evaluated. The major study finding was that the risk of major morbidity and mortality decreased with increasing body weight, plateauing at a body weight of approximately $4.5 \mathrm{~kg}$. These results appeared independent of patient age, suggesting that weight, not age, is the salient patient variable that influences surgical risk. Similar results were found when pulmonary artery banding procedures were excluded from the analysis. $^{1}$

Although these results are not particularly groundbreaking, the study by Inohara and colleagues ${ }^{1}$ appears to be the current authority on this topic, because it represents

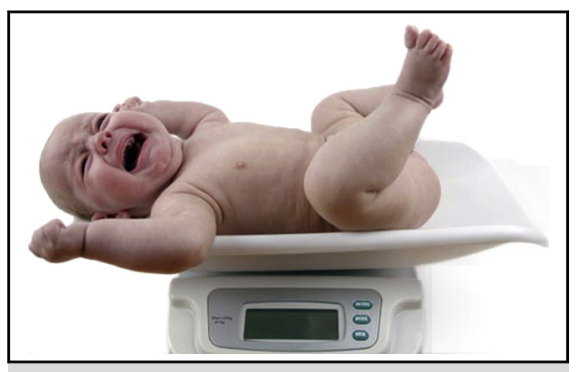

Does waiting for weight gain improve outcomes of VSD repair?

\section{Central Message}

A large contemporary study from Japan confirms that outcomes of surgical VSD repair are improved when children weigh more than $4.5 \mathrm{~kg}$.

See Article page 1132.

a well-conducted analysis of a large multi-institutional database of contemporary surgical outcomes. Further, the patients studied were highly representative of "routine" VSD repairs performed in daily practice. For instance, $96 \%$ of operations were coded as elective, the median preoperative length of stay was only 3 days, only $5 \%$ of children were on intravenous medications, the defects were primarily low-risk lesions ( $\sim 80 \%$ membranous and $10 \%$ outlet VSDs), and concomitant procedures were minor. However, even under these relatively low-risk circumstances, weight remained significantly associated with outcomes. The rate of death or major complications was approximately $60 \%$ higher $(7.2 \%$ vs $4.5 \%$ ) for patients undergoing surgery below the median body weight of the study, including higher rates of death, chylothorax, and unplanned cardiac reoperation. Thus, the study is notable because it objectively reaffirms the widely held opinion that patient size does, indeed, affect the hazard function of even a straightforward operation.

The study by Inohara and colleagues ${ }^{1}$ can be used to inform and support current clinical practice in several ways. The results suggest that surgical VSD closure should be delayed until $4.5 \mathrm{~kg}$ in asymptomatic or mildly symptomatic children who are demonstrating steady weight gain on an ambulatory heart failure regimen. For children who are unable to achieve a target weight of $4.5 \mathrm{~kg}$ before surgery, any incremental weight gain still 
appears to reduce surgical risk. Last, for patients with truly stagnant weight gain or severe symptoms who do require operation at small size, important prognostic information is provided.

\section{Reference}

1. Inohara T, Ichihara N, Kohsaka S, Miyata H, Hirata Y, Murakami A, et al. The effect of body weight in infants undergoing ventricular septal defect closure: a report from the Nationwide Japanese Congenital Surgical Database. J Thorac Cardiovasc Surg. 2019;157:1132-41. 